\title{
Experimental identification of the equivalent conductive resistance of a thermal elementary model of an induction machine
}

\author{
R. Khaldi, N. Benamrouche, M. Bouheraoua \\ LATAGE Laboratory, Department of Electrical Engineering, Mouloud Mammeri University, Tizi-Ouzou, Algeria \\ Email address: \\ khaldi_rabah@yahoo.fr(R. Khaldi), benamrouchen@yahoo.com (N. Benamrouche), Bouheraoua@hotmail.com (M. Bouheraoua)
}

To cite this article:

R. Khaldi, N. Benamrouche, M. Bouheraoua. Experimental Identification of the Equivalent Conductive Resistance of a Thermal Elementary Model of an Induction Machine. American Journal of Electrical Power and Energy Systems. Vol. 3, No. 2, 2014, pp. 15-20. doi: $10.11648 /$ j.epes.20140302.11

\begin{abstract}
This paper proposes a basic thermal model to estimate the temperature in different points of an induction motor, totally enclosed with external ventilation, for different loads at steady state. This basic model consists simply of a conductive thermal resistance for each point considered in the machine. Thereafter, the intermediates thermal resistances of conduction of the model are deduced. This approach is very easy to implement, requiring no geometrical data, or thermo-physical coefficients, or complex methods of implementation of a thermal model. Indeed, by knowledge of total losses in the machine, the temperature of the carcass, and the temperature of any point inside of the latter allows to deduct the equivalent thermal resistance of conduction of the different points and so the corresponding temperature.
\end{abstract}

Keywords: Induction Motor, Temperature, Heating, Conductive Resistance, Thermal Model

\section{Introduction}

The thermal performance of an electrical machine are crucial to guarantee its lifetime and thus to establish periods of maintenance. The insulation system of the motor and the lubricant deteriorate, and duration of life is reduced by half for each increase of temperature of 8 to $12^{\circ} \mathrm{C}$ [1].

The large number of works that are performed to study the thermal behavior of electric machines by detailed thermal models [2-9, 19] and simplified [10-13, 17, 18], shows the complexity of thermal phenomena come into play in these machines. These models are based on a nodal network of various dimensional interconnect by convective, conductive and radiative thermal resistances. Often to determine the latter, using semi-empirical relationships involving dimensionless numbers, especially for convection coefficients (particularly at the air gap). The difficulty also lies in the determination of contact resistance stator iron-frame requiring experimental tests for calibration [14]. All these models require a perfect knowledge of the geometry and physical properties of all elements constituting the machine.

On the other hand, the distribution of losses must be accurately known in the various constituent elements heat sources of the thermal problem.

Nowadays, iron and additional losses are always news about their assessment accurately [15, 16] and [9].

In this paper, one frees oneself of all the data needed, using a thermal model elementary of the motor, simply represented by a single equivalent conductive resistance. The total losses constitute the only source of heat in the machine, and are imposed at the point considered.

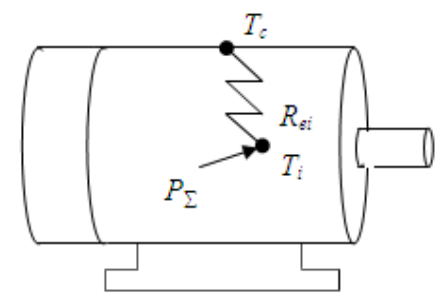

Figure 1. Circuit diagram of the elementary thermal model of an asynchronous machine

Figure 1 shows a diagram of the elementary thermal model where:

$T_{c}$ : carcass temperature

$T_{i}$ : Temperature of the point considered inside of the machine.

$R_{e i}$ : Equivalent conductive resistance 
$P_{\Sigma}:$ Total losses in the machine.

Generally the equation of heat in the thermal network is represented by the thermal bilan:

$$
P_{i}=C_{i} \frac{d T_{i}}{d t}+\sum_{i=1}^{N} \frac{\left(T_{i}-T_{j}\right)}{R_{i j}}
$$

where:

$P_{i}:$ Losses in the i part machine

$C_{i}$ : Thermal capacitie

$T_{j}:$ Temperature of the adjacent point considered

$R_{i j}$ : Conductive resistance between the node $\mathrm{i}$ and $\mathrm{j}$

The equation of heat to the thermal mode established is expressed by (1) when $j=c$ and $R_{i j}=R_{e i}$ :

$$
P_{\Sigma}=\frac{T_{i}-T_{c}}{R_{e i}}
$$

The conduction resistance equivalent in function of the load of a given point of the machine can be deduced from two tests: nominal load and empty (or half load). The other point's just one test. Subsequently, the conductive resistance between points (nodes) of the model are easily deduced.

\section{Experimental Procedure}

The basic test rig consists of a three-phase cage induction motor of $2.2 \mathrm{~kW}, 380 \mathrm{~V}, 5.2 \mathrm{~A}, \Delta$ connection, $1420 \mathrm{rpm}$, mechanically coupled to a dc machine with separate excitation. A variable voltage three-phase $50 \mathrm{~Hz}$ is used to supply the motor test.

The material used in the tests is shown in Fig.2.

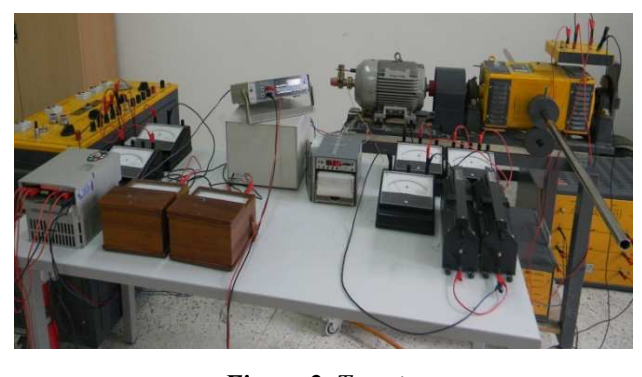

Figure 2. Test rig.

Several tests are carried out on the machine studied. The temperature measurement at various points in the machine tested, it is obtained using eight temperature sensors (thermocouples) placed in strategic locations on the motor.

The machine is loaded until thermal equilibrium is reached. Then, the final temperature, torque, current, voltage, the power absorbed and speed are recorded.

\subsection{Location of Sensors}

At the fixed part of the machine the sensors are placed more or less easily. From the moment that the machine is already realized, the sensor slot stator is placed in the space between the conductors and the insulating spacer closing.

The end winding, iron and of the tooth on the front are easily installed. At the air gap, we took advantage of the void left by the slots for the introduction, since the thickness of air gap is very small.

By cons, in the rotor, the investment is less easy as long as this part is rotating. The thermocouple is placed in a corresponding hole on the short-circuit ring. The signal issued by the latter is achieved through a system of rings and brushes made. The voltage drop across the sensor, resulting from the use of this method is systematically corrected. This drop is easily determined by a test drive of the motor under test, not powered by a DC motor.

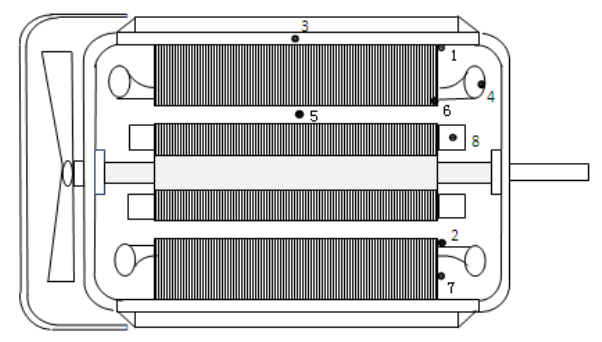

1: Iron-frame, 2: stator tooth, 3: Frame, 4: end winding, 5: air gap, 6: slot winding, 7: stator yoke, 8 : short-circuit ring rotor.

Figure 3. Location of sensors.

\section{Estimation of Equivalent Conductive Resistance}

Total losses $\left(P_{\Sigma}\right)$ of the motor can be easily deduced from the difference between power input $\left(P_{i n}\right)$ and power output $\left(P_{\text {out }}\right)$.

$$
P_{\Sigma}=P_{\text {in }}-P_{\text {out }}
$$

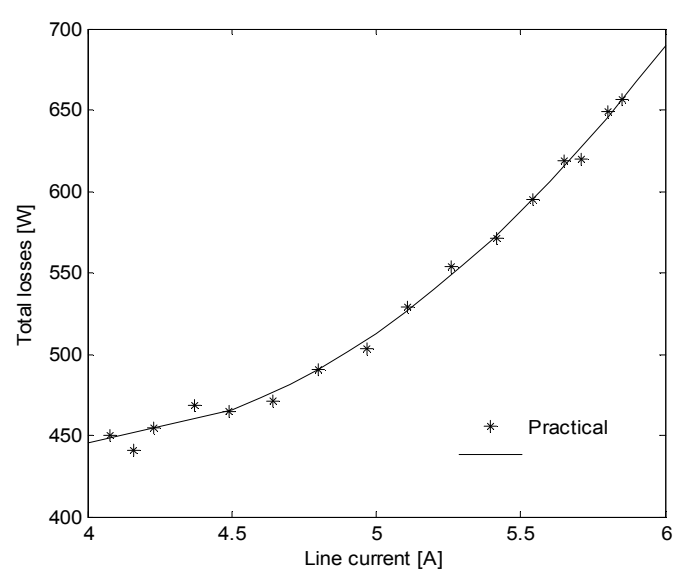

Figure 4. Total losses as a function of load current

The Fig. 4 above shows the total losses according to the load current of the motor. The experimental points are extrapolated by a polynomial function cut the ordinate axis by a point-coordinated (no load current, total losses to empty) Fig. 4.

The temperature difference between the frame and a point considered inside the machine is shown in Fig. 5. The 
experimental points are extrapolated, for a given point, by a polynomial function of second order.

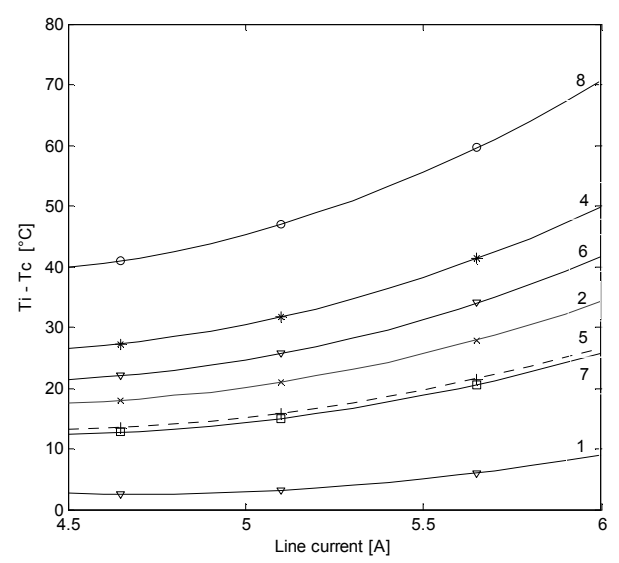

Figure 5. $(T i-T c)$ as a function of load current.

On Figure 6 and 7 are shown the equivalent thermal resistance of the stator winding based on total losses and current load, respectively, where the experimental points are extrapolated by a polynomial function.

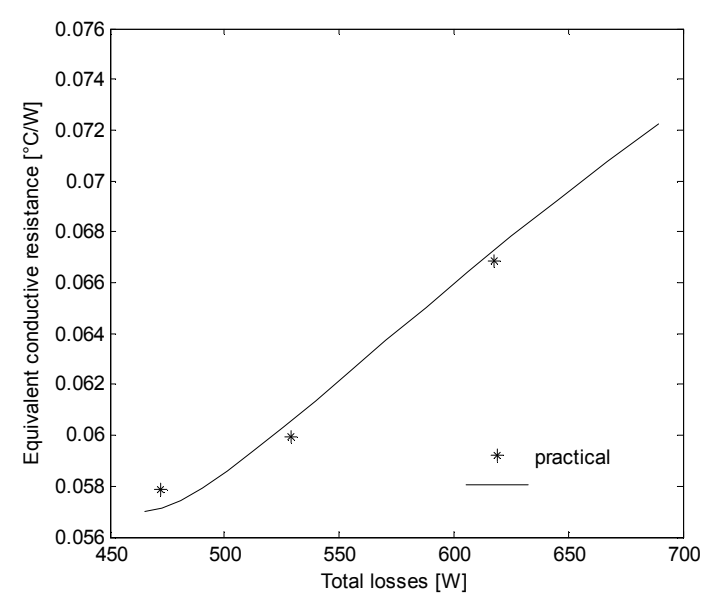

Figure 6. The equivalent conductive resistance of the end winding according to the total losses.

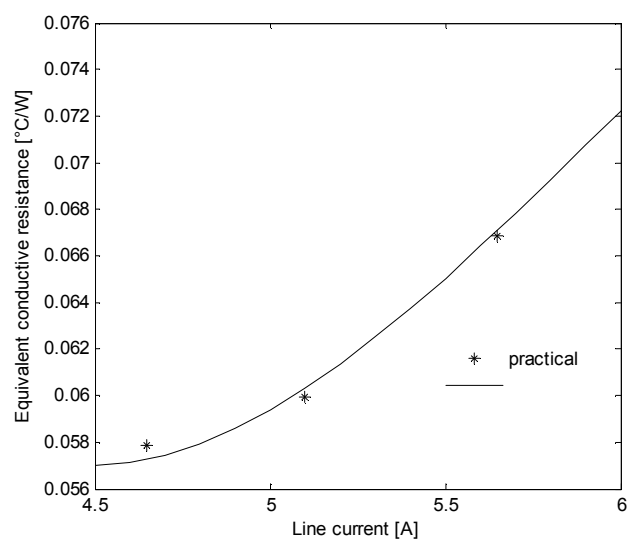

Figure 7. The equivalent conductive resistance of the end winding according to the load current.

The conductive resistance equivalent to the other points are deducted by a single heating test (half load test for example). This allows us to have the gap conductive resistance between points and considered the reference point in thermal regime established. These differences in absolute values are respectively:

Table 1. Difference Between Equivalent Conduction Resistance of Different Points in the machine compared of that End winding.

\begin{tabular}{lll}
\hline Point considered & Difference $\left[{ }^{\circ} \mathbf{C} / \mathbf{W}\right]$ & $\begin{array}{l}\text { Equivalent } \\
\text { conductive resistance } \\
{\left[{ }^{\circ} \mathbf{C} / \mathbf{W}\right]}\end{array}$ \\
\hline $\begin{array}{l}\text { Rotor (8) } \\
\text { Stator yoke (7) }\end{array}$ & 0.0287 & 0.0858 \\
Iron-frame (1) & 0.0305 & 0.0266 \\
Air gap (5) & 0.0518 & 0.0053 \\
End winding (4), & 0.0289 & 0.0283 \\
(reference) & 0.0000 & 0.0571 \\
Slot winding (6) & 0.0111 & 0.0461 \\
Stator tooth (2) & 0.0194 & 0.0377 \\
\hline
\end{tabular}

The equivalent of the conduction resistance of experimental point of reference (end winding (4)) is:

$R_{e i}=0.0571^{\circ} \mathrm{C} / \mathrm{W}$, the motor operating half load.

It can be seen in Table I, the equivalent conduction resistance of the rotor is the most important. This corresponds to reality where the rotor temperature is the most important in a cage induction machine (Fig. 5). By cons, that of the stator-frame interface is lowest (Fig. 5). This is certainly due to the proximity of the interface of the stator frame.

Are then obtained parallel lines (Figure 8) to the line shown in Figure 6 with the differences in Table 1.

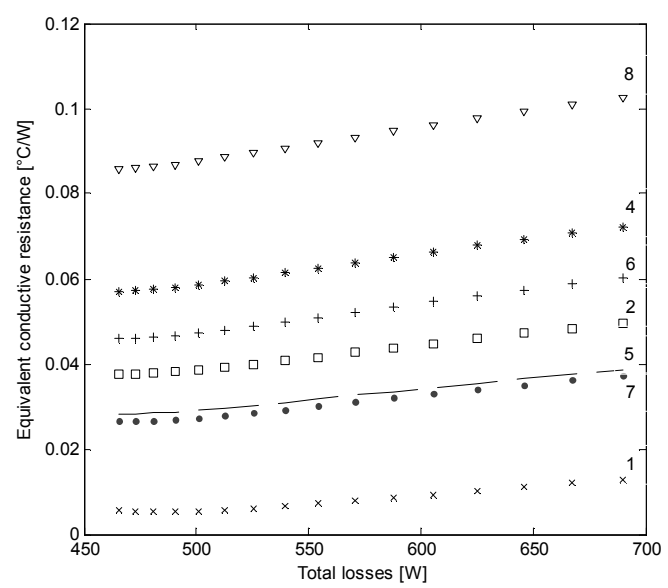

Figure 8. Equivalent conductive resistance according to total losses.

Knowing the conduction resistance of the equivalent points $(1,2,4,5,6,7,8)$ Figure 8 , from the point situated on the carcass, one can obtain the equivalent resistance of conduction between the different points on using the following equations:

$$
\begin{aligned}
& R_{73}=R_{71}+R_{13} \\
R_{63}= & R_{67}+R_{71}+R_{13}
\end{aligned}
$$




$$
\begin{gathered}
R_{23}=R_{27}+R_{71}+R_{13} \\
R_{53}=R_{56}+R_{67}+R_{71}+R_{13}
\end{gathered}
$$

or

$$
\begin{aligned}
& R_{53}=R_{52}+R_{27}+R_{71}+R_{13} \\
& R_{43}=R_{46}+R_{67}+R_{71}+R_{13} \\
& R_{83}=R_{85}+R_{56}+R_{67}+R_{71}+R_{13}
\end{aligned}
$$

or

$$
\mathrm{R}_{83}=\mathrm{R}_{85}+\mathrm{R}_{52}+\mathrm{R}_{27}+\mathrm{R}_{71}+\mathrm{R}_{13}
$$

Where:

$R_{73}, R_{63}, R_{23}, R_{53}, R_{43}, R_{83}$ : Equivalent conductive resistance between considered node and the frame.

$R_{71}, R_{13}, R_{27}, R_{56}, R_{67}, R_{52}, R_{46}, R_{85}$ : the intermediate equivalent conductive resistance.

The reference point (end windings) $R_{43}$ is fully known. Knowing the gap of thermal conduction resistances equivalent of the various points (Table I), relative to that of the end winding, it is deduced the value of resistance easily intermediate heat.

Then we deduce the overall thermal elementary model with the thermal conductive resistances of interconnection between different nodes shown in Figure 9.

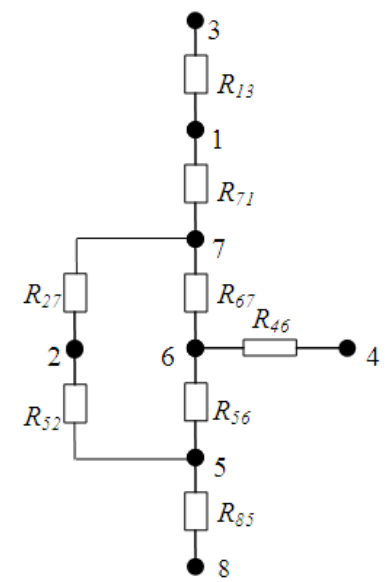

Figure 9. An thermal elementary model decomposed of cage induction machine.

The value of these resistances is given in the following table 2 .

All of these intermediate thermal resistances are constant, except $R_{13}$ is given by the following equation:

$$
\mathrm{R}_{13}=\mathrm{R}_{43}+\Delta \mathrm{R}_{13}
$$

Where:

$\Delta R_{13}$ : represents the difference of the value of the thermal resistance of the interface (iron-carcass) to the end winding. In our case: $\Delta R_{13}=0.0518^{\circ} \mathrm{C} / \mathrm{W}$.

$$
\mathrm{R}_{43}=\mathrm{a} * \mathrm{P}_{\Sigma}+\mathrm{b}
$$

with:

$a, b:$ are constants (in our case:

$\left.a=7.100813 \mathrm{E}-05^{\circ} \mathrm{C} / \mathrm{W}^{2}, b=0.023265036^{\circ} \mathrm{C} / \mathrm{W}\right)$ and, $P_{\Sigma .}$ total losses in induction machine.

Table 2. The Intermediate Thermal Resistances of Conduction of The Thermal Model

\begin{tabular}{ll}
\hline $\begin{array}{l}\text { The intermediate thermal } \\
\text { resistances of conduction }\end{array}$ & Values in $\left[{ }^{\circ} \mathrm{C} / \mathrm{W}\right]$ \\
\hline$R_{71}$ & 0.0213 \\
$R_{67}$ & 0.0195 \\
$R_{27}$ & 0.0111 \\
$R_{56}$ & -0.0178 \\
$R_{52}$ & -0.0094 \\
$R_{46}$ & 0.0111 \\
$R_{85}$ & 0.0576 \\
\hline
\end{tabular}

\section{Results}

Figures 10, 11 and 12 represent the temperature of the carcass, at the thermal regime established for different loads, depending on the temperature of the point considered, respectively of the end winding, of the stator yoke, the rotor, the iron-frame, of the air gap, the stator slot and finally the stator tooth. In these figures, are shown the theoretical curves and experimental points with an offset for certain points not exceeding $5^{\circ} \mathrm{C}$, as shown in Table III. The accuracy of the results depends mainly on test conditions and measurements. Specifically, measurement of total losses and temperatures.

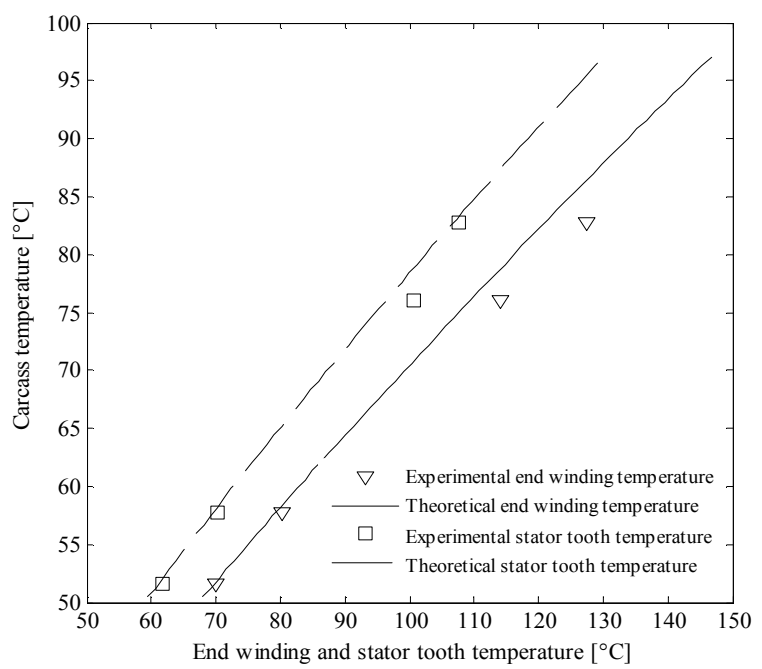

Figure 10. The frame temperature according to the end winding and the stator tooth temperature.

The ambient temperature is taken into account by the theoretical model as a given. In this case it is equal to $30^{\circ}$ C.

The following table shows the comparison in results obtained by test and those by the thermal elementary model. 


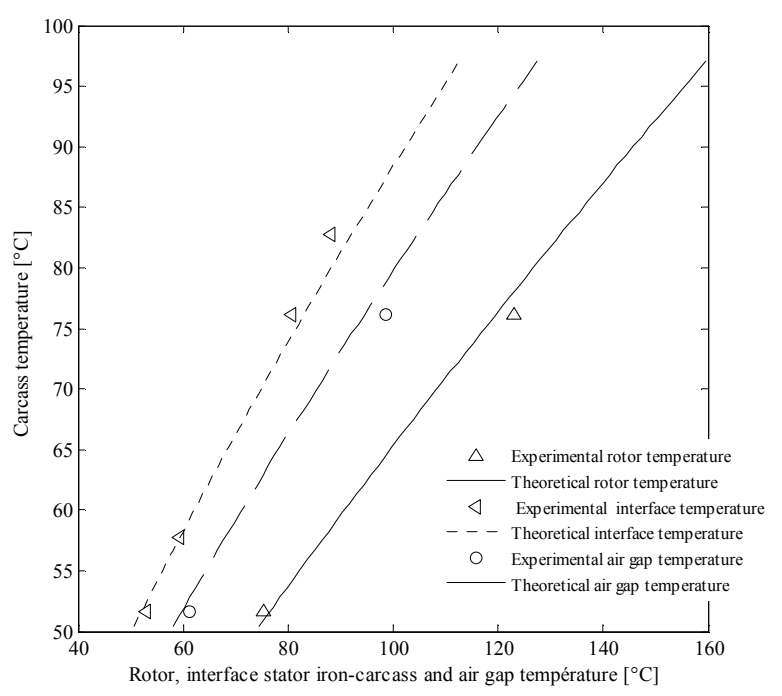

Figure 11. The frame temperature according to the rotor, interface iron-carcass and air gap temperature.

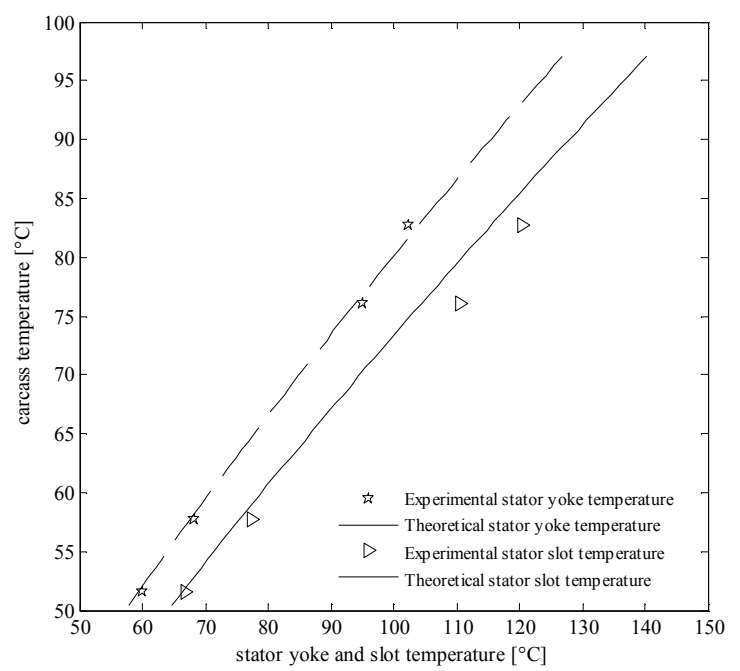

Figure 12. The frame Temperature according to the slot and the stator yoke temperature.

Table 3. Comparison of Theoretical and Practical Temperatures at No-load and Full load at Steady State

\begin{tabular}{lllll}
\hline $\begin{array}{l}\text { Temperature of the } \\
\text { point considered } \\
\text { Point considered }\end{array}$ & \multicolumn{2}{l}{ Practice $\left[{ }^{\circ} \mathbf{C}\right]$} & \multicolumn{2}{c}{ Theoretical $\left[{ }^{\circ} \mathbf{C}\right]$} \\
\hline Rotor (8) & 75.23 & 122.9 & 75.85 & 120.86 \\
Stator yoke (7) & 60.10 & 95.10 & 58.90 & 95.07 \\
Iron-frame (1) & 53.00 & 80.60 & 51.60 & 83.94 \\
Air gap (5) & 61.15 & 98.70 & 60.23 & 97.09 \\
End winding (4) & 70.00 & 114 & 69.20 & 110.74 \\
Slot winding (6) & 66.90 & 110 & 65.88 & 105.69 \\
Stator tooth (2) & 61.70 & 100.60 & 60.57 & 97.60 \\
Frame (3) & 51.60 & 76.10 & 51.25 & 76.85 \\
\hline
\end{tabular}

These results show an acceptable agreement between the points of experimental measurements and theoretical curves, as shown in Table III, in number, for the heating test at no-load and full load at steady state.

Therefore the thermal elementary model presented in this paper can be validated and applied to the permanent thermal regime for different charge of the induction machine studied.

The model thermal, shown on Figure 9, shows that for an asynchronous machine of given materials construction, the contact conductive resistance is a very important factor in heat transfer.

Finally, the application of this thermal elementary model allows us to deduce the temperature of the internal parts of the machine with sufficient accuracy, by the knowledge of the carcass temperature, load current (total losses) and ambient temperature.

The temperature of the carcass can also be easily obtained by an infrared camera Fig. 13.

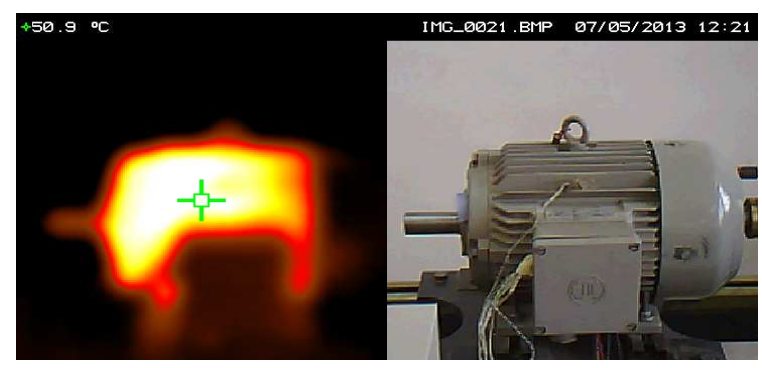

Figure 13. The frame Temperature obtained by an infrared camera.

\section{Conclusion}

In this paper, a thermal elementary model of an asynchronous machine with self-ventilated cage is presented.

This model is characterized by single equivalent conduction resistance and whose determination is very easy. Indeed two heating runs suffice for identifying for one a given point.

This method allows us to overcome the knowledge of the loss distribution in the different materials. This is because the total losses are introduced in a concentrated manner at the point considered. It also does not require geometric data and thermo-physical factors, the various constituents' material of machine. It is shown in this paper that for a given material of construction for an asynchronous machine, the contact resistance iron-carcass is a major factor in heat transfer.

The results show a maximum of about $5^{\circ} \mathrm{C}$ difference for some points, between the theoretical curves and experimental points. This difference can certainly be reduced by more accurate measurements of total losses and temperatures.

Finally, this model can be easily applied to a series of asynchronous machine to provide the temperature inside of the machine at the points considered.

\section{References}

[1] M. Kostenko et L. Piotrovski, "Machines Electriques," Tome II, Machines à Courant Alternatif, $3{ }^{\text {ème }}$ édition, Mir-Moscou, 765 p., 1979. 
[2] A. Boglietti, A. Cavagnino, and D. Staton, M. Shanel, M. Mueller and C. Mejuto, "Evolution and Modern Approaches for Thermal Analysis of electrical machines," IEEE Trans. On indust. Electronics, vol. 56, No. 3, pp. 871-882, March 2009.

[3] J. F. Trigeol, Y. bertin, and P. Lagonotte "Thermal Modeling of an Induction Machine through the Association of Two Numerical Approches," IEEE Trans. On Energy conversion, vol. 21, No. 2, pp. 314-323, June 2006.

[4] D. Staton, A. Boglietti, and A. Cavagnino, "Solving the More Difficult Aspects of Electric Motor Thermal Analysis in Small and medium Size Industrial Induction Motors," IEEE Trans. On Energy conversion, vol. 20, No. 3, pp. 620-628, September 2005

[5] O. I. Okoro, "Steady and Transient states thermal Analysis of Induction Machine at Blocked rotor Operation," European trans. On Electr. Power, pp. 109-120, October 2005.

[6] G. Kylander, "Thermal Modelling of small Cage Induction Motors," Int. symp., 1995, On Elect. Power Engin., pp. 235-240.

[7] P. H. Mellor, D. Roberts, and D. R. Turner, " Lumped parameter thermal model for electrical machines of TEFC design," in Proc., Sep. 1991 IEE, vol. 138, No. 5, pp. 205-218.

[8] R. Glises, A. Miraoui, and M. Kauffmann, "Thermal modelling for induction motor," J. Phys. III France 3, September 1993, pp. 1849-1859.

[9] A. Bousbaine, W. F. Low, M. McCormick and N. Benamrouche, "Thermal modelling of induction motors based on accurate loss density measurements," ICEM, Sept. 1992, pp. 953-957.

[10] C. A. Cezário and H. P. Silva, " Electric Motor Winding Temperature Prediction Using a Simple Two-Resistance Thermal Circuit," Proc. of the 2008 International Conference on Electrical Machines, IEEE, Paper ID 1383, pp.1-3.
[11] N. Jaljal, J. F. Trigeol, and P. Lagonotte "Reduced Thermal Model of an induction Machine for real-time thermal Monitoring," IEEE Trans. On Indust. Electronics, vol. 55, No. 10, pp. 3535-3542, October 2008.

[12] A. L. Shenkman, and M. Cherktov, "Experimental Method for Synthesis of generalized Thermal Circuit of Polyphase induction Motors," IEEE Trans. On Energy conversion, vol. 15, No. 3, pp. 264-268, September 2000.

[13] J. T. Boys, M. J. Miles, "Empirical thermal model for inverter-driven cage induction machines," IEE Proc-Electr. Power Appl., vol. 141, No.6, pp. 360-372, Nov. 1994.

[14] J. F. Moreno, F. P. Hidalgo and M. D. Martinez, "Realisation of the tests to determine the parameters of the thermal model of an induction machine," in Sept. 2001 IEE, Proc.-Electr. Power App., vol. 148, No.5, pp. 393-397.

[15] A. Bousbaine, W. F. Low, and M. McCormick, "Novel approach to measurements of iron and stray load losses in induction motors," in Proc. 1996 IEE, vol. 143, No. 1, pp. 78-86.

[16] E. Olivier, R. Perret and J. Perard, "Localization of the losses in an induction machine supplied by an inverter," Electric Machines and power Systems, No. 9, pp. 401-412, 1984.

[17] M. Aníbal Valenzuela, and Pablo Reyes, "Simple and reliable Model for the Thermal Protection of Variable-Speed Self-Ventilated Induction MotorDrives," IEEE Transactions of Industriy Applications, Vol. 46, No. 2, pp. 770-778, March/April 2010.

[18] M.J. Picazo-Ródenas, R. Royo, J. Antonino-Daviu, J. Roger-Folch, "Use of the infrared data for heating curve computation induction motors Application to fault diagnosis" Engineering Failure Analysis, Vol. 35, pp. 178-192, 15 December 2013.

[19] Kai Li, Shaoping Wang, John P. Sullivan, "A novel thermal network for the maximum temperature-rise of hollow cylinder," Applied Thermal Engineering, Vol. 52, Issue 1, pp. 198-208, 5 April 2013. 